\title{
Comments on the paper
}

\author{
"High doses of riboflavin and the elimination of dietary red meat \\ promote the recovery of some motor functions in Parkinson's disease \\ patients. C.G. Coimbra and V.B.C. Junqueira. Brazilian Journal of Medical \\ and Biological Research, 36: 1409-1417, 2003"
}

H.B. Ferraz ${ }^{1}$, E.A.B. Quagliato ${ }^{2}$, C.R.M. Rieder ${ }^{3}$, D.J. Silva ${ }^{4}$, H.A.G. Teive ${ }^{5}$, E.R. Barbosa ${ }^{6}$, F. Cardoso ${ }^{7}$, J.C.P. Limongi ${ }^{6}$, J.M.F. Bezerra ${ }^{8}$, L.A.F. Andrade ${ }^{9}$, N. Allam ${ }^{10}$, R.C.P. Prado ${ }^{11}$ and V. Tumas ${ }^{12}$

\author{
Correspondence \\ Correspondence - Comments \\ H.B. Ferraz \\ Setor de Distúrbios do Movimento \\ EPM, UNIFESP \\ Rua Botucatu, 740 \\ 04023-900 São Paulo, SP \\ Brasil \\ Correspondence - Response \\ C.G. Coimbra \\ Departamento de Neurologia e \\ Neurocirurgia \\ EPM, UNIFESP \\ Rua Pedro de Toledo, 781, 7으andar \\ 04039-032 São Paulo, SP \\ Brasil \\ Fax: +55-11-5539-3123 \\ E-mail: coimbracg.nexp@epm.br \\ $\ldots \ldots \ldots \ldots \ldots \ldots . . . . . . . .$.
}

Key words

- Parkinson's disease

- Riboflavin

- FAD

- Glutathione

- Iron

- Hemin

Received May 17, 2004

Accepted July 14, 2004

\author{
1Setor de Distúrbios do Movimento, Escola Paulista de Medicina, \\ Universidade Federal de São Paulo, São Paulo, SP, Brasil \\ ${ }^{2}$ Ambulatório de Distúrbios do Movimento, Departamento de Neurologia, \\ Universidade Estadual de Campinas, Campinas, SP, Brasil \\ ${ }^{3}$ Setor de Distúrbios do Movimento, Hospital de Clínicas de \\ Porto Alegre, Porto Alegre, RS, Brasil \\ ${ }^{4}$ Unidade de Parkinson e Desordens do Movimento, Centro de Transtornos do Movimento, Hospital \\ das Clínicas, Universidade Federal de Goiás, Goiânia, GO, Brasil \\ ${ }^{5}$ Setor de Distúrbios do Movimento, Hospital das Clínicas, \\ Universidade Federal do Paraná, Curitiba, PR, Brasil \\ ${ }^{6}$ Setor de Distúrbios do Movimento, Hospital das Clínicas, Faculdade de Medicina, Universidade de \\ São Paulo, São Paulo, SP, Brasil \\ ${ }^{7}$ Setor de Distúrbios do Movimento, Universidade Federal de Minas Gerais, \\ Belo Horizonte, MG, Brasil \\ ${ }^{8}$ Universidade Estadual do Rio de Janeiro, and Ambulatório de Distúrbios do Movimento, Hospital \\ do Servidor Público Estadual, Rio de Janeiro, RJ, Brasil \\ ${ }^{9}$ Hospital do Servidor Público Estadual de São Paulo, São Paulo, SP, Brasil \\ ${ }^{10}$ Ambulatório de Distúrbios do Movimento, Hospital de Base do Distrito Federal, Brasília, DF, Brasil \\ ${ }^{11}$ Ambulatório de Parkinson e Distúrbios do Movimento, Hospital Universitário, Universidade Federal \\ de Sergipe, Aracaju, SE, Brasil \\ ${ }^{12}$ Ambulatório de Distúrbios do Movimento, Hospital das Clínicas, Faculdade de Medicina de \\ Ribeirão Preto, Universidade de São Paulo, Ribeirão Preto, SP, Brasil
}

We are being questioned by our colleagues and patients about a paper published in the Brazilian Journal of Medical and Biological Research by Coimbra and Junqueira (1). The authors analyzed the effect of oral vitamin B2 (riboflavin) and the dietary restriction of red meat in 31 patients with Parkinson's disease (PD). The authors found that the dietary intervention and the prescription of riboflavin induced a significant improvement in the clinical condition of their patients and stated that this regimen should be recom- mended to PD patients. In our opinion, this article has many methodological problems, which were surprisingly neglected by this peer-reviewed journal.

The authors made an open-label experiment not controlled with placebo. They selected the patients, evaluated them, recommended the dietary restriction, and prescribed vitamin B2. At the end of a 6-month period the authors themselves reevaluated the patients and concluded for an improvement on motor scales. This type of non-blinded ex- 
periment can lead to biased estimated differences between pre- and post-therapeutic intervention. In addition, there would have been no ethical problems if placebo tablets had been administered to some of the patients since the conventional treatment of PD could have been maintained in both groups.

Patients who were instructed to refrain from red meat should be warned about receiving another source of protein to prevent malnutrition. It is well known that protein, especially neutral amino acids, in the small intestine and blood stream competes with the intestinal absorption and with the brain penetration of levodopa $(2,3)$. Thus, it may be speculated that the putative motor improvement found in PD patients under dietary protein restriction could be attributed to the increased bioavailability of levodopa in the brain. To minimize this bias, the authors should have recommended to their patients not to take their oral levodopa doses together with protein intake in the evaluation prior to vitamin B2 administration and to dietary intervention.

The authors did not report in their paper the reasons why 12 patients dropped out of the study. We do not know if there were adverse effects or if the patients experienced worsening of their clinical status. Also, the authors only analyzed the outcomes of the 19 patients who remained on the dietary and vitamin B2 regimen. It is highly recommended in good scientific practice to analyze the outcomes including the data for patients who dropped out (intention-to-treat analysis).

Serum vitamin B2 levels in PD patients were compared with those of 10 patients with "dementia". We know that "dementia" is too generic a term and the authors do not report the etiology of the disease in the 10 "demented" patients, which could obviously interfere with the serum measurements of vitamin B2. There are different criteria to establish the diagnosis of dementia and the authors did not disclose their criteria. Pa- tients with memory complaints or even with established dementia usually take oral multivitamin preparations and this could also interfere with the blood measurements, i.e., demented patients could in fact have high vitamin B2 levels and PD patients could have normal levels. The authors do not mention if there is a study reporting the normal range of blood vitamin B2 levels in a Brazilian population. As far as we know, such a study has not been done.

The main outcome measure used was a new motor scale created by the authors of the paper. They made a modification to the Hoehn and Yahr scale, which is not used to rate motor performance but to rate $\mathrm{PD}$ patients at five different stages. Motor performance is best evaluated by the Unified Parkinson's Disease Rating Scale, which is a validated and widely used scale (4). If the authors wished to use their own scale they should have validated it before collecting the data.

The authors do not report if they evaluated the patients during the "off" or "on" state of the levodopa effect. Fluctuation of motor performance is observed in more than $50 \%$ of the patients after five years of treatment and an uncontrolled motor status evaluation of the patients at baseline and after 6 months would be an important source of bias.

Previous epidemiological studies with case-control methodology have failed to demonstrate any correlation between life-style or food habits and Parkinson's disease (5-7). There is no scientific evidence correlating vitamin B2 or protein consumption and Parkinson's disease in previous well-controlled studies $(8,9)$ analyzing a much higher number of individuals than the 31 patients studied by Coimbra and Junqueira (1).

In summary, there is no current scientific evidence that vitamin B2 consumption and dietary red meat restriction can benefit patients with Parkinson's disease. 


\title{
References
}

1. Coimbra CG \& Junqueira VBC (2003). High doses of riboflavin and the elimination of dietary red meat promote the recovery of some motor functions in Parkinson's disease patients. Brazilian Journal of Medical and Biological Research, 36: 1409-1417.

2. Pare S, Burr SI \& Ross SE (1992). Effect of daytime protein restriction on nutrient intakes of freeliving Parkinson's disease patients. American Journal of Clinical Nutrition, 55: 701-707.

3. Simon N, Gantcheva R, Bruguerolle B \& Viallet F (2004). The effects of a normal protein diet on levodopa plasma kinetics in advanced Parkinson's disease. Parkinsonism and Related Disorders, 10: 137-142.

4. Fahn S, Elton RL \& Members of the UPDRS Development Committee (1987). Unified Parkinson's Disease Rating Scale. In: Fahn S, Marsden CD, Calne DB \& Goldstein M (Editors), Recent Developments in Parkinson's Disease. Vol. 2. MacMillan Health Care Information, Florham Park, NJ, USA, 153-164.

5. Baldereschi M, DiCarlo A, Vanni P, Ghetti A, Carbonin P, Amaducci L \& Inzitani D (2003). Italian longitudinal study on aging working group. Lifestyle related risk factors for Parkinson's disease: a populational study. Acta Neurologica Scandinavica, 108: 239-244.

6. Tsai CH, Lo SK, See LC, Chen HZ, Chen RS, Weng YH, Chang FC \& Lu CS (2002). Environmental risk factors of young onset Parkinson's disease. Clinical Neurology and Neurosurgery, 104: 328-333.

7. Tanner CM (1994). Epidemiological clues to the cause of Parkinson's disease. In: Marsden CD \& Fahn S (Editors), Movement Disorders 3. Butterworth-Heinemann, Oxford, UK, 124-146.

8. Golbe LI, Farrel TM \& Davis PH (1988). Casecontrol study of early life dietary factors in Parkinson's disease. Archives of Neurology, 45: 350353.

9. Abbot RD, Ross GW, White CR, Sanderson WT, Burchfiel CM, Kashon M, Sharp DS, Masaki KH, Curb JD \& Petrovitch H (2003). Environment, lifestyle, and physical precursors of clinical Parkinson's disease: recent findings from the Honolulu-Asia aging study. Journal of Neurology, 250 (Suppl 3): III-30-III-39.

\section{Response to the Comments of H.B. Ferraz et al.}

\author{
C.G. Coimbra ${ }^{1,2}$ and V.B.C. Junqueira ${ }^{3,4}$
}

\begin{abstract}
${ }^{1}$ Setor de Neurologia, Hospital do Servidor Público Municipal de São Paulo, São Paulo, SP, Brasil ${ }^{2}$ Departamento de Neurologia e Neurocirurgia, and ${ }^{3}$ Disciplina de Geriatria, Departamento de Medicina, Centro de Estudos do Envelhecimento, Universidade Federal de São Paulo, São Paulo, $\mathrm{SP}$, Brasil

${ }^{4}$ VIT $€$ - Cromatografia Líquida em Análises Clínicas S/C Ltda., São Paulo, SP, Brasil
\end{abstract}

We have reported a steady and progressive improvement of motor capacity in 19 sporadic Parkinson's disease (PD) patients treated with high doses (30 mg orally every $8 \mathrm{~h}$ ) of riboflavin plus elimination of dietary red meat for 6 months (1). The treatment was based on the following preliminary observations: I) 31 of 31 consecutively evaluated PD patients were found to have an altered enzyme glutathione reductase activation coefficient (EGR-AC) and low plasma levels of flavin adenine dinucleotide (FAD) compared to the internationally determined normal range of FAD (125-300) and to local non-PD patients suffering from other neurodegenerative conditions (dementia without a clinical history or computed tomography scan images compatible with stroke), and II) 19 PD patients were found to consume large quantities of red meat $(2,044 \pm 1,439 \mathrm{~g} /$ week) compared with 19 sex-matched controls of similar age from the same social environment (789 $\pm 509 \mathrm{~g} /$ week). Since all PD patients had a normal dietary content of riboflavin, we proposed that I) PD patients may be a subset of the large group of indi- 
viduals (10-15\% of the general population) expressing flavokinase (FK) with low substrate affinity (poor absorbers of vitamin B2; Ref. 2), and II) a high dietary red meat consumption might trigger PD in predisposed individuals (expressing altered FK). A review of the metabolic pathways requiring the participation of both vitamin B2 active forms (flavin mononucleotide and FAD) indicated that the association of low riboflavin absorption and high dietary red meat consumption (high dietary hemin production) might account for most (if not all) neurochemical changes reported in PD including glutathione depletion, impaired mitochondrial complex I activity, mtDNA mutations, disturbed iron metabolism, and $6(\mathrm{OH})$ dopamine formation (1).

By searching the current medical literature, Ferraz and associates might readily become familiar with countless preliminary studies which have been subsequently confirmed by larger and better controlled research. The two consecutive articles by Schoenen et al. $(3,4)$ on the effects of high doses of riboflavin on migraine may afford an appropriate example. Preliminary reports are commonly submitted to communicate novel findings of potentially large benefit: further research by others is thus facilitated. Our initial report (1) was clearly presented as preliminary work being part of ongoing research.

A placebo effect is highly unlikely to account for our results. Goetz et al. (5) observed placebo-associated motor improvements in only $16 \%$ of 105 PD subjects evaluated at 4, 12 and 24 weeks of treatment, and demonstrated that none of them showed improvement at all three evaluations. Their observations contrast sharply with the initially rapid and then slowly progressive improvement found in all (100\%) 19 PD patients in our own study (1). All patients were fully informed about the meaning of "red meat" and unequivocally advised to replace it with another protein source. The timing of levodopa administrations relative to meals did not change during treatment and would not explain the motor improvement found between pre- and post-therapeutic intervention. Now, after more than 18 months of sustained treatment, none of our 19 patients has experienced any deterioration of motor capacity, and some have experienced further motor improvement, although no additional patient (apart from the initial 3 subjects) has become symptom-free.

None of our initial 31 patients "dropped out" of the study: 12 were excluded (by the time the manuscript was submitted to this journal, 2 of them had bone fractures that prevented adequate motor evaluation, and one died of metastasis from thyroid carcinoma - all 3 before completing 3 months of therapy; the remaining 9 patients took erratic daily doses of riboflavin - confirmed by uncorrected EGR-AC and plasma FAD, or did not comply with full elimination of dietary red meat, or had recently initiated the treatment). There is long established evidence (6) that orally administered riboflavin is non-toxic (doses higher than $30 \mathrm{mg}$ lead to decreased net absorption), and much higher doses ( $400 \mathrm{mg} /$ day) have been safely given to humans $(3,4)$.

Heterogeneous control groups (composed of patients suffering from different diseases) have long been employed in clinical research to establish whether a particular feature differentiates a specific disease from others. In addition, researchers may be dealing with a heterogeneous group of neurodegenerative diseases even when the currently employed clinical diagnostic criteria for dementia of the Alzheimer type are strictly fulfilled without a brain tissue biopsy. Our study has demonstrated that lower plasma concentrations of FAD differentiate PD patients from a clearly defined group of subjects with neurodegenerative disorders without Parkinsonism. Moreover, when the levels found in both groups of Brazilian patients were compared with the internationally determined 
normal range of plasma FAD concentrations and EGR-AC levels, we observed deficient riboflavin status in all 31 consecutively evaluated PD patients but in only 3 of 10 control subjects. Therefore, the lack of population studies addressing the normal range of FAD among Brazilian inhabitants does not invalidate our data. In addition, none of our PD or control patients was malnourished or taking tablets containing riboflavin. Therefore, when analyzing the ethical issues involved in using placebo tablets in control groups of PD patients during blinded studies, one should consider the risk of aggravating permanent neurological deficits by postponing the correction of documented riboflavin deficiency.

The 5 consecutive stages reported by Hoehn and Yahr (7) are specifically based on the progressive motor disabilities of PD patients and on nothing else. Their validated scale has been widely used to characterize the degree of motor deterioration of PD patients. In our own percent rating system we followed the same sequence of events, although fragmented so as to detect motor improvements in a more sensitive manner. For instance, late stage IV (nearly full dependence for daily care) was differentiated from early stage IV (assistance required for only the few most delicate or difficult items like shaving and putting on socks).

Because only some of our patients were in the advanced disease stage exhibiting the "on-off" phenomenon, all patients were uniformly rated early in the morning, prior to the earliest administration of symptomatic drugs for PD. This timing usually coincides with the "off" state for those with advanced PD showing motor fluctuations and dyskinesias related to levodopa therapy.

All studies cited by Ferraz and associates (their Refs. 5 to 9), presented to contest our results, surprisingly contain no data on red meat consumption (as distinguished from the general protein consumption), laboratory evaluation of vitamin B2 status or the effects of high doses of riboflavin on $\mathrm{PD}$ patients. Two of them (their Refs. 5 and 6) did not even inquire about food habits, and in one (their Ref. 8) the authors confined their inquiry to "food and vegetables eaten raw, with seeds that are either swallowed or scraped with the teeth" in a search for a heatlabile component similar to that found in the seeds of the cycad plant which grows only in Guam and neighboring islands. Abbot et al. (their Ref. 9) reported a similar daily intake of riboflavin by PD patients and controls - a finding fully consistent with our own report on normal dietary content of riboflavin associated with low plasma levels of FAD and altered EGR-AC. The citations made by Ferraz and associates demonstrate that they have completely missed our point, even though it was clearly emphasized even in the title of our study (1). In addition to the chapter by Tanner (Ref. 37 of our preliminary report, Ref. 1), neglected by Ferraz and associates (while citing much older work by the same group: their Ref. 7), recent work has characterized the consumption of raw meat (8) and high intake of iron (9) as risk factors for PD.

Our inexpensive therapy (1) addresses the cause of PD and, rather than merely alleviating the symptoms (the major goal of the costly palliative treatments available), may provide partial disease regression even in the more advanced stages and, when administered to recent onset PD patients, may even lead to the asymptomatic state. In addition, nobody can register patent rights for riboflavin. Therefore, if properly considered by patients and colleagues, the confirmation of our results (allied to an early PD diagnosis and identification of predisposed subjects) may dramatically reduce the incidence of this disease, thereby alleviating the related burden on public and private health insurance systems. Ferraz and associates may best serve the interests of their questioning patients and colleagues by conducting their own study on this subject. 


\section{References}

1. Coimbra CG \& Junqueira VBC (2003). High doses of riboflavin and the elimination of dietary red meat promote the recovery of some motor functions in Parkinson's disease patients. Brazilian Journal of Medical and Biological Research, 36: 1409-1417.

2. Anderson BB, Scattoni M, Perry GM, Galvan P, Giuberti M, Buonocore G \& Vullo C (1994). Is the flavin-deficient red blood cell common in Maremma, Italy, an important defense against malaria in this area? American Journal of Human Genetics, 55: 975-980.

3. Schoenen J, Lenaerts M \& Bastings E (1994). High-dose riboflavin as a prophylactic treatment of migraine: results of an open pilot study. Cephalalgia, 14: 328-329.

4. Schoenen J, Jacquy J \& Lenaerts M (1998). Effectiveness of high-dose riboflavin in migraine prophylaxis. A randomized controlled trial. Neurology, 50: 466-470.

5. Goetz CG, Leurgans S, Raman R \& Stebbins GT (2000). Objective changes in motor function dur- ing placebo treatment in PD. Neurology, 54: 710 714.

6. Zempleni J, Galloway JR \& McCormick DB (1996) Pharmacokinetics of orally and intravenously administered riboflavin in healthy humans. American Journal of Clinical Nutrition, 63: 54-66.

7. Hoehn MM \& Yahr MD (1967). Parkinsonism: onset, progression and mortality. Neurology, 17: 427-442

8. Hellenbrand W, Seidler A, Boeing H, Robra BP, Vieregge P, Nischan P, Joerg J, Oertel WH, Schneider E \& UIm G (1996). Diet and Parkinson's disease. I. A possible role for the past intake of specific foods and food groups. Results from a self-administered food-frequency questionnaire in a case-control study. Neurology, 47: 636-643.

9. Powers KM, Smith-Weller T, Franklin GM Longstreth WT, Swanson PD \& Checkoway $H$ (2003). Parkinson's disease risks associated with dietary iron, manganese, and other nutrient intakes. Neurology, 60: 1761-1766. 